\title{
Systematic atlasing in Hessequa - Report on the first cycle of seasonal monitoring
}

\author{
Johan A van Rooyen \& Les G Underhill
}

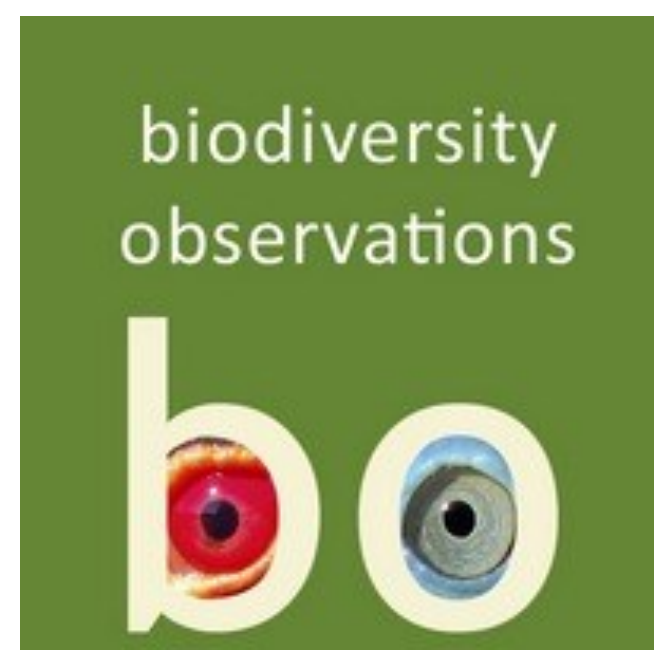

Van Rooyen JA \& Underhill LG 2020. Systematic atlasing in Hessequa - Report on the first cycle of seasonal monitoring. Biodiversity Observations 11.3:1-14

Bird atlas, citizen science, Hessequa, monitoring 


\section{Ornithology}

\section{Systematic atlasing in Hessequa - Report on the first cycle of seasonal monitoring}

\author{
Johan A. van Rooyen, U3A Stilbaai Bird Group \\ email: rooyenvanjohan@gmail.com
}

Les G. Underhill, Animal Demography Unit, Department of Biological Sciences, University of Cape Town, Rondebosch, 7701, and Biodiversity and Development Institute, Gunners Park, Gunners Circle, Epping

\section{Introduction}

The Second Southern African Bird Atlas Project (SABAP2) started in July 2007, with the objective of mapping the distributions of bird species in South Africa, Lesotho and Swaziland. This citizen science project has a clearly defined fieldwork protocol and uses spatial units called pentads which are five minutes of latitude north to south and five minutes of longitude east to west (Underhill 2016, Underhill \& Brooks 2016). SABAP2 is now one of the longest running bird atlas projects ever, and the emphasis has shifted from the project being a snapshot of bird distributions at a point in time to a project which is measuring how distributions are changing in time. The initial focus on mapping in SABAP2 has shifted to a focus on monitoring (Underhill et al. 2017).

\begin{abstract}
Bird atlasing in the Hessequa region of the Western Cape has progressed beyond mapping to monitoring. During a three-year period within 2014/17, the U3A Stilbaai Bird Group upgraded the distribution maps using a strategy which aimed to even out coverage per grid cell, and achieve minimum mapping standards. In the two-year period December 2017 to November 2019, the group implemented a new strategy that would result in each of the 75 pentads in the Hessequa Atlas Area being atlased in each of the four seasons over a two-year period. Using a chessboard pattern to split the 75 pentads into two sets, the first set was atlased in summer and winter in the first year and autumn and spring of the second year. The second set was atlased in autumn and spring of the first year, and summer and winter of the second year. This paper reports the successful completion of the first monitoring cycle.
\end{abstract}

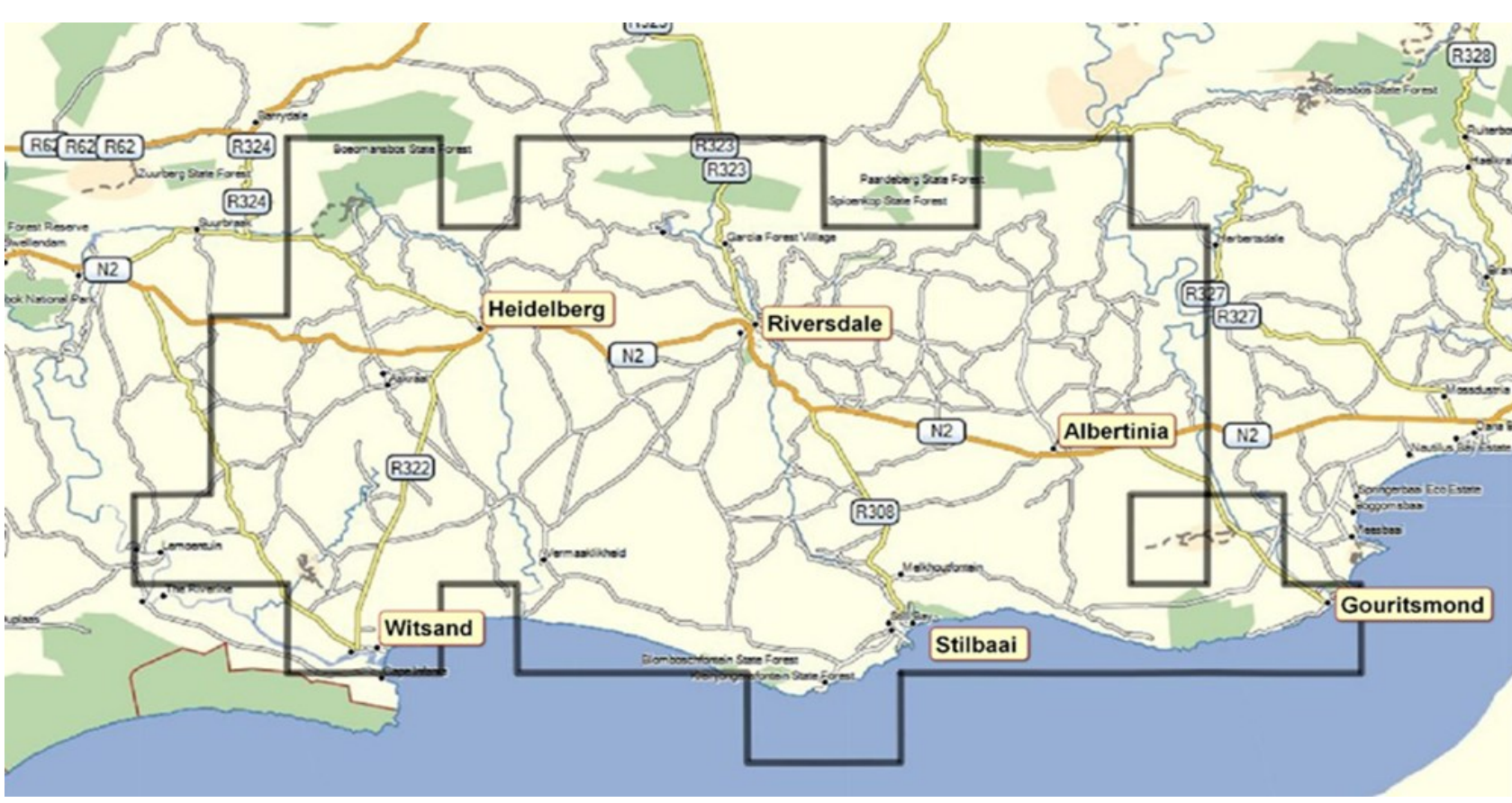

Figure 1. The overall boundary of the 75 SABAP2 pentads forming the Hessequa Atlas Area at the eastern end of the Overberg, Western Cape, South Africa (van Rooyen 2018). 


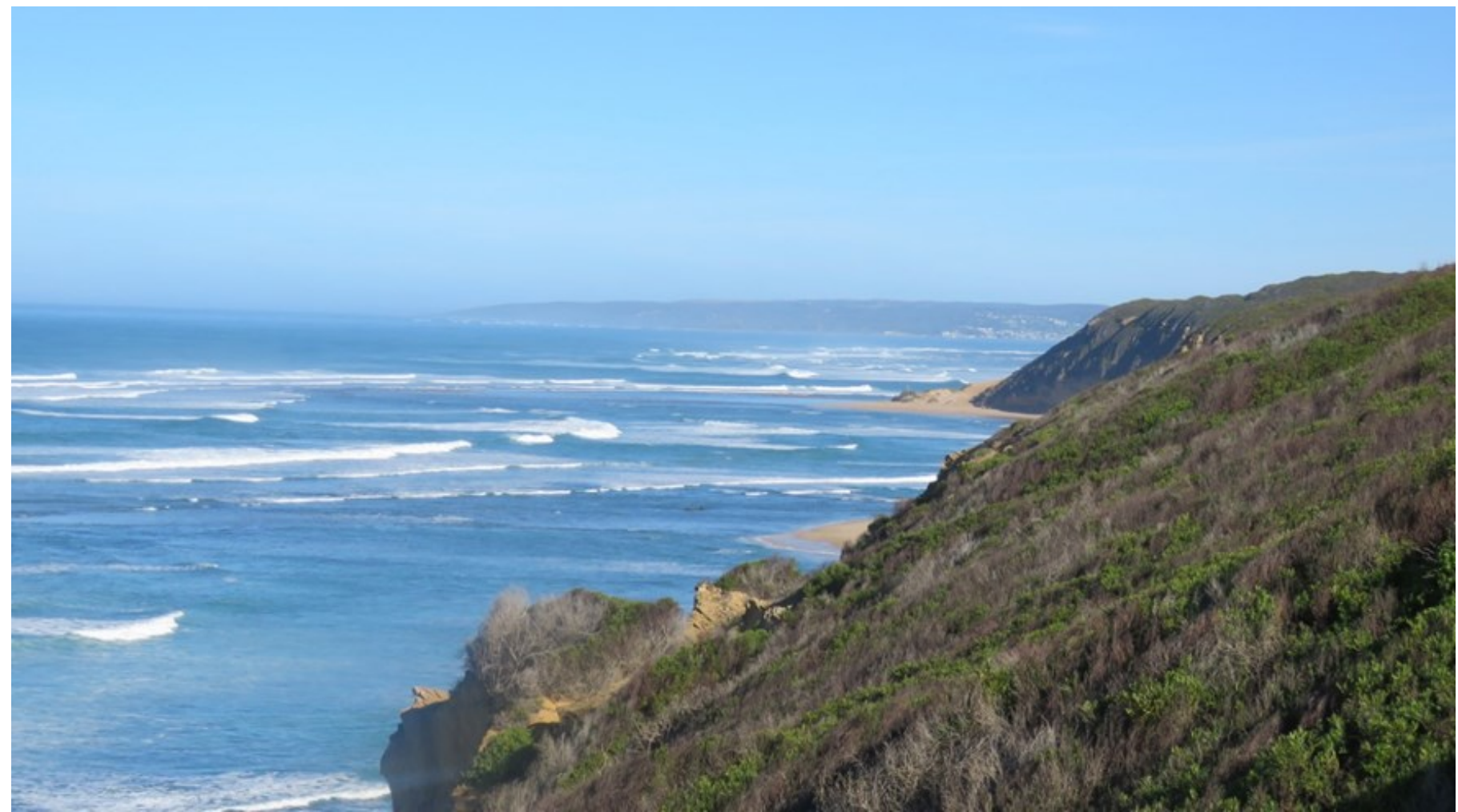

Plate 1. The coastline, looking westwards from Geelkrans, towards Stilbaai and Jongensfontein. had submitted 539 full-protocol checklists, and visiting atlasers a further 200 , and every grid cell in the area had achieved a foundational coverage of at least seven fullprotocol checklists (van Rooyen 2018). A "full-protocol checklist" requires a minimum of two hours of fieldwork (Underhill 2016).

Van Rooyen (2018) described a strategy for shifting the focus of the U3A Stilbaai Bird Group from foundational coverage to seasonal monitoring in two-year cycles. This paper reports the progress towards meeting the targets between December 2017 and November 2019. It also describes overall progress with the project in the region, and considers the strategies in place to enable the project to achieve its monitoring targets. It compares checklists submitted by members of the Bird Group with those submitted by visiting atlasers.

The U3A Stilbaai Bird Group (U3A Stilbaai 2015) adopted this citizen science project in 2014, and defined the "Hessequa Atlas Area" as an area consisting of 75 pentads (Figure 1) (van Rooyen 2018). The area coincides closely with the borders of the Hessequa Municipality which falls administratively within the Eden District; it lies at the eastern end of the part of the Western Cape popularly referred to as the Overberg (van Rooyen 2018). The chosen area lies between the Langeberg mountain range and the sea and the dominant land use is mixed agriculture (mainly barley, wheat, canola, sheep and cattle); the • foothills of the Langeberg form the northern boundary and there is natural vegetation along the coast in the south (Plates 1-6). Atlas fieldwork started in October 2014; by November 2017 the Bird Group •

\section{Methods}

\section{Seasonal monitoring objectives}

The monitoring strategy proposed by van Rooyen (2018) can be summarized as follows. Four seasons were defined:

- Summer - December, January and February

Autumn - March, April and May

Winter - June, July and August

Spring - September, October and November. 

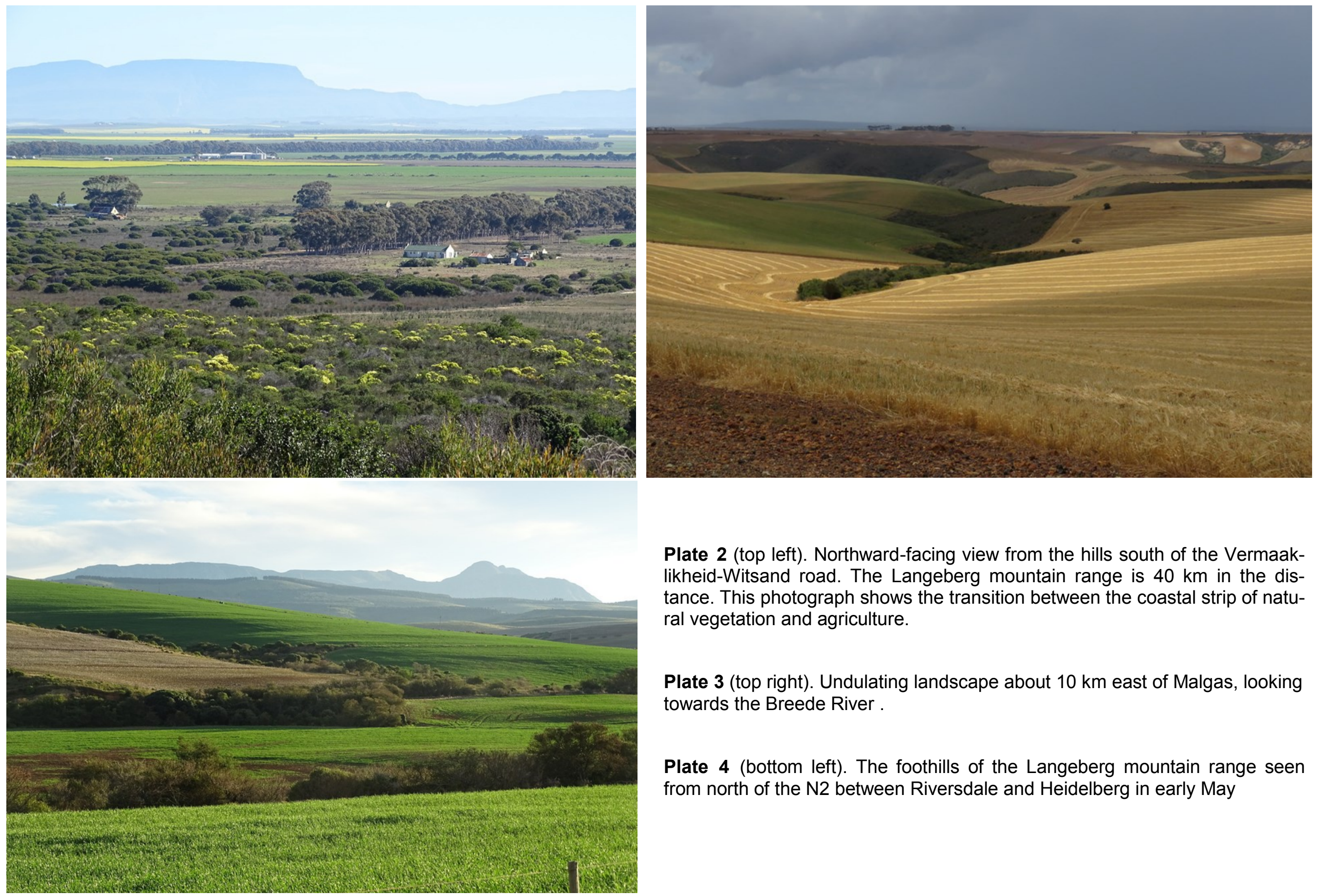

Plate 2 (top left). Northward-facing view from the hills south of the Vermaaklikheid-Witsand road. The Langeberg mountain range is $40 \mathrm{~km}$ in the distance. This photograph shows the transition between the coastal strip of natural vegetation and agriculture.

Plate 3 (top right). Undulating landscape about $10 \mathrm{~km}$ east of Malgas, looking towards the Breede River.

Plate 4 (bottom left). The foothills of the Langeberg mountain range seen from north of the N2 between Riversdale and Heidelberg in early May 


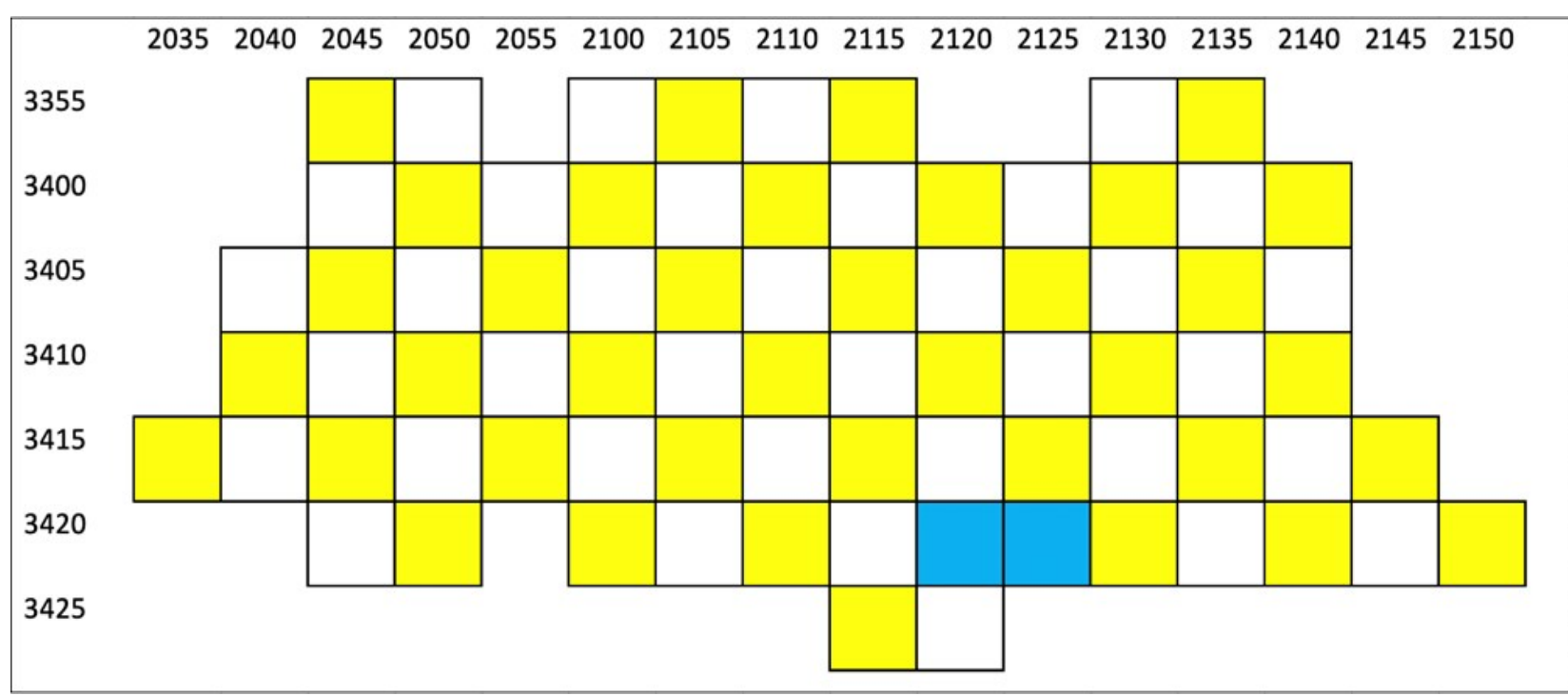

Figure 2. Chessboard pattern of the pentads of the Hessequa Atlas Area. Pentads shaded yellow are scheduled for fieldwork in summer and winter of Year 1, and in autumn and spring of Year 2, and vice versa for the white pentads. The two Stilbaai pentads, 3420_2120 and 3420_2125, which are scheduled for monthly fieldwork are shaded blue. seasonal distribution of checklists; however, within a season the month with the smallest number of full protocol checklists is to be selected for atlasing. In order to achieve this monitoring objective, 170 fullprotocol checklists are required per reporting year, or about 14 per month.

Checklists submitted by "visiting" atlasers are welcomed. Atlasing members of the U3A Stilbaai Bird Group can do additional atlasing if they want to. However, these checklists are not included in the monitoring objectives.

Two considerations are needed to implement this strategy. (1) People are needed to do the fieldwork. (2) Access is needed to a good selection of farms and other properties in each pentad to do the fieldwork.
The reporting year was defined as 1 December to 30 November, because the calendar year would result in splitting "summer" across two years. After consideration of the human resources available the fieldwork targets were set as follows:

- The two "home" pentads around Stilbaai (3420_2120 and 3420_2125) to be atlased at least once every month.

- The remaining 73 pentads to be atlased twice a year, with fieldwork evenly distributed spatially and seasonally in a two-year chessboard pattern of "yellow" and "white" pentads (Figure 2):

- Year 1: Yellow pentads to be atlased during summer and winter. White pentads to be atlased during autumn and spring

- Year 2: White pentads to be atlased during summer and winter. Yellow pentads to be atlased during autumn and spring.

In addition, the number of checklists overall to be kept as evenly spread over the months as feasible. Thus, the main priority is the
(1) Each season, JAvR makes a list of the approximately 38 pentads to be atlased in that three-month period, and assigns a third of them to each month so as to even out the number of checklists received for each month overall. He sends the monthly list to the 16 atlasers of the U3A Stilbaai Bird Group (an atlaser often consists of a husband-wife team). The atlasers select which (if any) of the pentads they commit themselves to doing. The spreadsheets to undertake this strategy are maintained by JAvR.

(2) The U3A Stilbaai Bird Group maintains a database of the names and contact details of all the landowners with whom contact has previously been made during atlasing trips. Atlasers of the Bird Group are provided with maps showing the landowners and contact details. Atlasers inform the relevant landowners by WhatsApp or sms of their fieldwork plans in advance. All atlasers carry the project identification 
with the project details so that atlasers are easily identified. All additional landowners encountered 3355 during fieldwork are encouraged to provide their contact details, and are added to the database, which is maintained in Dropbox.

Checklists for the Hessequa Atlas Area submitted by the U3A Stilbaai Bird Group over the two-year review period are compared with those submitted by 3420 visiting atlasers. The average number of hours spent atlasing per checklist is compared for the two ${ }^{3425}$ groups. The average number of species recorded after one hour, two hours and the total for the Figure 3. Numbers of full protocol SABAP2 checklists per pentad in the Hessequa Atlas Region checklist are also computed and compared between from the start of the bird atlas in July 2007 to November 2017 (van Rooyen 2018). groups.

\section{Results}

Overall progress with SABAP2 mapping from 1 July 2007 to 30 November 2019

To place the monitoring component into context, we first describe the overall progress for the Hessequa Atlas Area during the two-year period from December 2017 to November 2019. At the start of the review period, the total number of checklists submitted up to November 2017 was 1,232; the minimum number of checklists per pentad was eight, the maximum was 125 in pentad 34202120 , and 28 pentads had more than 10 checklists (Figure 3 ).

During the two-year review period, 524 full protocol checklists were submitted, bringing the total to 1756; the minimum number of

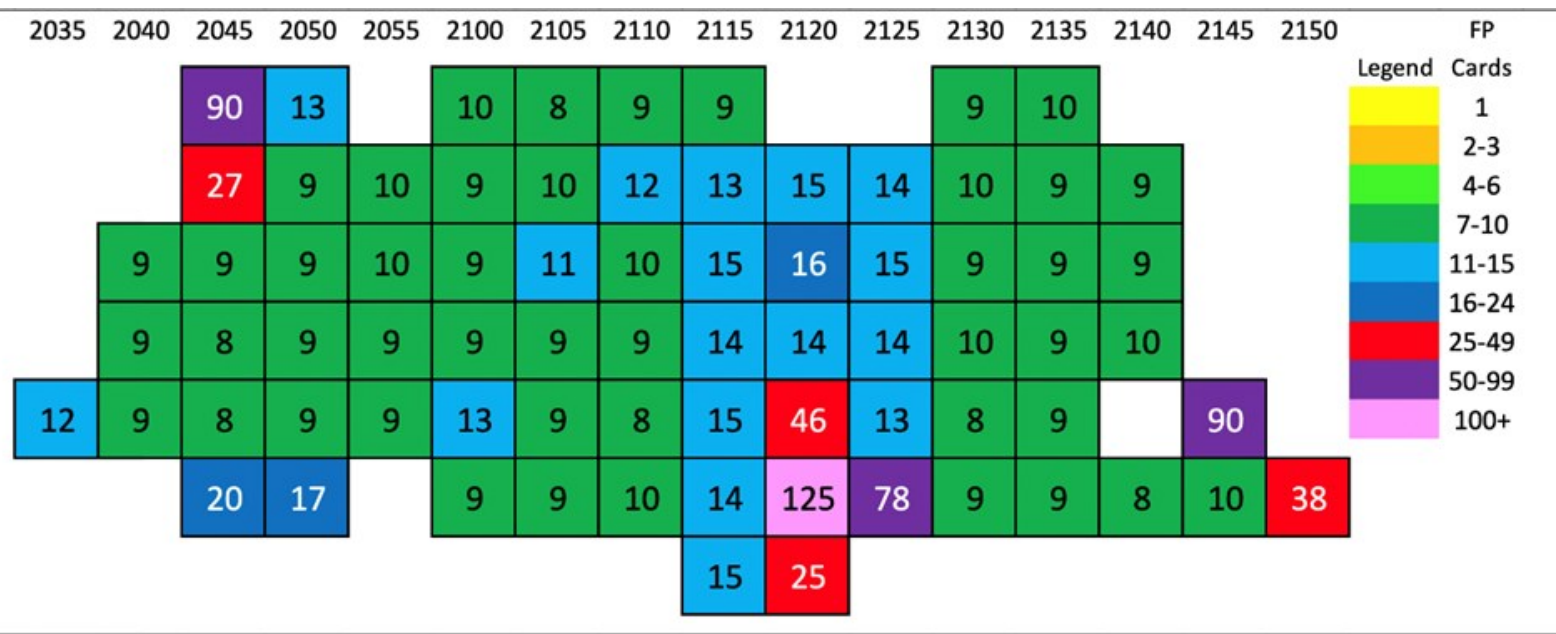

\begin{tabular}{|c|c|c|c|c|c|c|c|c|c|c|c|c|c|c|c|c|c|c|}
\hline & 2035 & 2040 & 2045 & 2050 & 2055 & 2100 & 2105 & 2110 & 2115 & 2120 & 2125 & 2130 & 2135 & 2140 & 2145 & 2150 & & FP \\
\hline 3355 & & & 107 & 17 & & 14 & 13 & 13 & 13 & & & 13 & 14 & & & & Legend & $\begin{array}{c}\text { Cards } \\
1\end{array}$ \\
\hline 3400 & & & 35 & 14 & 15 & 14 & 14 & 18 & 18 & 19 & 19 & 14 & 14 & 15 & & & & $\begin{array}{l}2-3 \\
4-6\end{array}$ \\
\hline 3405 & & 13 & 13 & 14 & 14 & 14 & 15 & 14 & 21 & 22 & 19 & 13 & 13 & 15 & & & & $\begin{array}{c}7-10 \\
11-15\end{array}$ \\
\hline 3410 & & 13 & 13 & 13 & 13 & 13 & 13 & 13 & 20 & 18 & 19 & 14 & 14 & 14 & & & & $\begin{array}{l}16-24 \\
25-49\end{array}$ \\
\hline 3415 & 17 & 13 & 13 & 14 & 13 & 19 & 13 & 13 & 20 & 69 & 22 & 15 & 13 & & 101 & & & $\begin{array}{c}50-99 \\
100+\end{array}$ \\
\hline 3420 & & & 30 & 23 & & 17 & 13 & 16 & 21 & 179 & 117 & 14 & 14 & 17 & 19 & 60 & & \\
\hline 3425 & & & & & & & & & 24 & 34 & & & & & & & & \\
\hline
\end{tabular}

Figure 4. Overall numbers of full-protocol SABAP2 checklists per pentad in the Hessequa Atlas Region from the start of the bird atlas in July 2007 to November 2019.

checklists per pentad was 13 and 31 pentads had more than 15 checklists (Figure 4). 


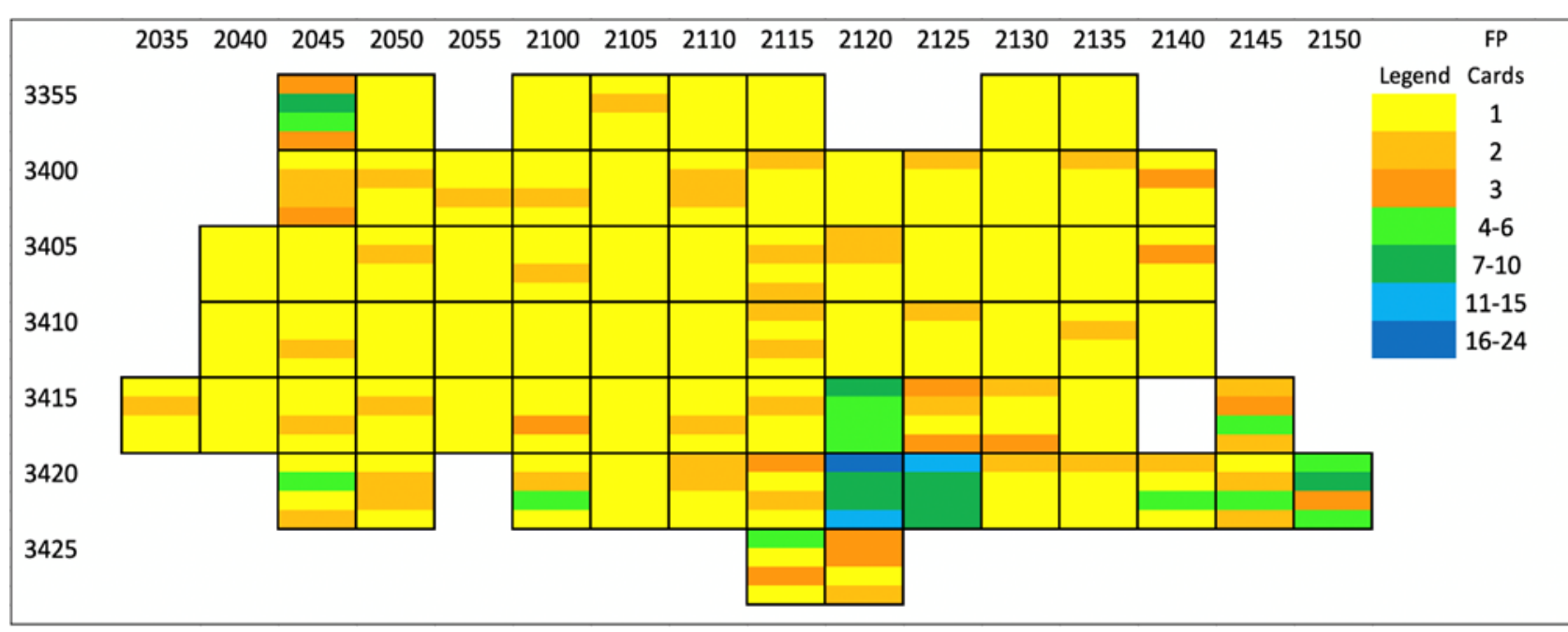

Figure 5. Seasonal presentation of the 524 full protocol checklists submitted in the Hessequa Atlas Area for the two years December 2017 to November 2019. Each pentad has been split horizontally into four bands, with summer at the top, and spring at the bottom. Colour coding is in the legend.

\begin{tabular}{|c|c|c|c|c|c|c|c|c|c|c|c|c|c|c|c|c|c|c|}
\hline & 2035 & 2040 & 2045 & 2050 & 2055 & 2100 & 2105 & 2110 & 2115 & 2120 & 2125 & 2130 & 2135 & 2140 & 2145 & 2150 & & FP \\
\hline 3355 & & & 17 & 4 & & 4 & 5 & 4 & 4 & & & 4 & 4 & & & & Legend & $\begin{array}{c}\text { Cards } \\
1\end{array}$ \\
\hline 3400 & & & 8 & 5 & 5 & 5 & 4 & 6 & 5 & 4 & 5 & 4 & 5 & 6 & & & & $4-6$ \\
\hline 3405 & & 4 & 4 & 5 & 4 & 5 & 4 & 4 & 6 & 6 & 4 & 4 & 4 & 6 & & & & $\begin{array}{c}7-10 \\
11-15\end{array}$ \\
\hline 3410 & & 4 & 5 & 4 & 4 & 4 & 4 & 4 & 6 & 4 & 5 & 4 & 5 & 4 & & & & $25-49$ \\
\hline 3415 & 5 & 4 & 5 & 5 & 4 & 6 & 4 & 5 & 5 & 23 & 9 & 7 & 4 & & 11 & & & $100+$ \\
\hline 3420 & & & 10 & 6 & & 8 & 4 & 6 & 7 & 54 & 39 & 5 & 5 & 9 & 9 & 22 & & \\
\hline 3425 & & & & & & & & & 9 & 9 & & & & & & & & \\
\hline
\end{tabular}

Figure 6. Numbers of full-protocol checklists per pentad for the two-year study period from December 2017 to November 2019 in the Hessequa Atlas Area.

\section{Progress with seasonal monitoring}

In each of the two years of the first monitoring cycle (December 2017 to November 2019) the targets of 170 checklists per year in the designated pentads were achieved by atlasers of the U3A Stilbaai Bird Group. In total, 524 full protocol checklists were submitted to SABAP2 from the Hessequa Atlas Area, 184 more than the minimum of 340 required to achieve the monitoring targets. Most of the additional checklists were submitted by visiting atlasers. As a result, 31 pentads have one checklist in every season, and 45 pentads have additional checklists in various seasons (Figure 5).

An alternative presentation of the 524 full-protocol checklists shows that 59 of the 75 pentads received between four and six checklists over the two-year period (Figure 6). Six pentads had 11 or more checklists. The two Stilbaai pentads, 34202120 and 3420_2125, had 54 and 39 checklists, respectively.

\section{Monthly distribution of full protocol checklists}

One of the targets of the U3A Stilbaai Bird Group has been to spread the full-protocol checklists as evenly as feasible across the months of the year. During the monthly allocation of pentads to atlasers, months with no checklists, or months with the smallest number of checklists were prioritised. At the end of November 2017, at the start of the two-year period under review, there were 11 pentads with at 
Cumulative monthly totals to end Nov 2019

Dec Jan Feb Mar Apr May Jun Jul Aug Sep Oct Nov

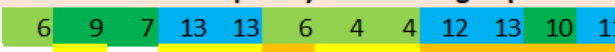

$\begin{array}{llllllllllll}0 & 1 & 0 & 1 & 1 & 2 & 1 & 1 & 2 & 3 & 2\end{array}$

$\begin{array}{llllllllllll}2 & 1 & 2 & 1 & 1 & 1 & 0 & 1 & 0 & 1 & 2 & 2\end{array}$

$\begin{array}{lllllllllllll}1 & 1 & 1 & 1 & 1 & 2 & 0 & 1 & 1 & 1 & 1 & 2\end{array}$

$\begin{array}{llllllllllll}2 & 0 & 1 & 1 & 2 & 1 & 1 & 1 & 1 & 2 & 1 & 0\end{array}$

$\begin{array}{llllllllllll}0 & 0 & 1 & 2 & 2 & 2 & 1 & 1 & 1 & 1 & 1 & 1\end{array}$

$\begin{array}{llllllllllll}1 & 1 & 2 & 1 & 2 & 0 & 1 & 1 & 2 & 1 & 1 & 0\end{array}$

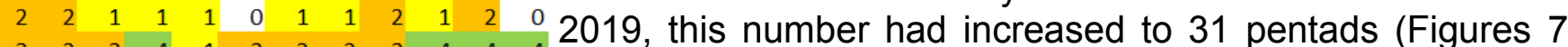

$\begin{array}{llllllllllll}3 & 2 & 3 & 4 & 1 & 3 & 2 & 2 & 3 & 4 & 4 & 4 \\ 1 & 1 & 1 & 2 & 1 & 1 & 1 & 1 & 2 & 1 & 1 & 1\end{array}$ and 8). The number of pentad-months with no checklists

$\begin{array}{lllllllllllll}1 & 1 & 1 & 2 & 1 & 1 & 1 & 1 & 2 & 1 & 1 & 1 & \text { (counted as the total number of zeros for a pentad across }\end{array}$

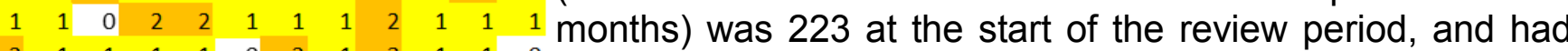

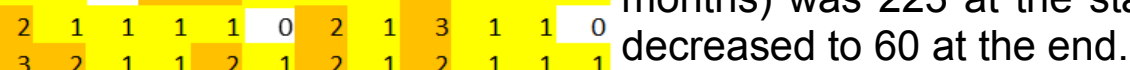

\begin{tabular}{lllllllllll}
3 & 2 & 1 & 1 & 2 & 1 & 2 & 1 & 2 & 1 & 1 \\
\hline
\end{tabular}

$\begin{array}{llllllllllll}2 & 2 & 2 & 2 & 2 & 1 & 1 & 1 & 2 & 1 & 1 & 1\end{array}$

$\begin{array}{llllllllllll}2 & 2 & 2 & 2 & 1 & 1 & 1 & 1 & 2 & 2 & 1 & 2 \\ 2 & 2 & 2 & 2 & 1 & 1 & 1 & 2 & 1 & 2 & 1 & 2\end{array}$

$\begin{array}{lllllllllll}2 & 2 & 2 & 2 & 1 & 1 & 1 & 2 & 1 & 2 & 1 \\ 2 & 2 & 1 & 1 & 1 & 0 & 1 & 1 & 1 & 1 & 1\end{array}$

$\begin{array}{llllllllllll}2 & 3 & 1 & 1 & 1 & 1 & 1 & 1 & 1 & 1 & 1 & 0\end{array}$

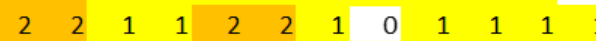

$\begin{array}{lllllllllllll}1 & 1 & 1 & 1 & 1 & 1 & 1 & 1 & 1 & 1 & 1 & 2\end{array}$

$\begin{array}{llllllllllll}1 & 0 & 1 & 1 & 1 & 1 & 1 & 1 & 2 & 1 & 1 & 2\end{array}$

$\begin{array}{llllllllllll}0 & 1 & 2 & 1 & 1 & 2 & 1 & 2 & 1 & 1 & 1 & 1 \\ 1 & 0 & 1 & 1 & 2 & 2 & 1 & 1 & 1 & 1 & 2 & 1\end{array}$ The sample sizes of checklists submitted by members of the

$\begin{array}{llllllllllll}1 & 1 & 1 & 2 & 1 & 1 & 1 & 2 & 2 & 1 & 1 & 0 \\ & \text { Stilbaai Bird Group and visiting atlasers are large enough for }\end{array}$

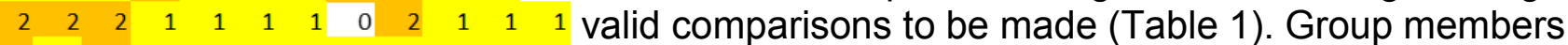

$\begin{array}{llllllllllll}2 & 1 & 2 & 1 & 1 & 1 & 1 & 1 & 1 & 1 & 1 & 1 \\ 2 & 2 & 2 & 1 & 2 & 2 & 1 & 2 & 1 & 2 & 2 & 2\end{array}$ spent an average of 5.2 hours per checklist whereas visitors

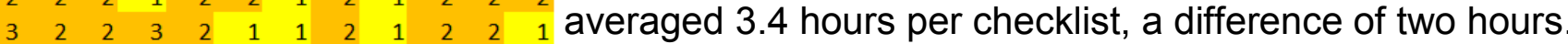

$\begin{array}{llllllllllll}2 & 1 & 2 & 2 & 1 & 1 & 2 & 1 & 2 & 2 & 1 & 2\end{array}$ The average number of species per checklist after one hour

$\begin{array}{llllllllllll}2 & 1 & 2 & 1 & 1 & 1 & 0 & 1 & 1 & 1 & 1 & 1 \\ \text { and two hours were similar. However the total number of }\end{array}$

$\begin{array}{lllllllllllllll}2 & 2 & 1 & 1 & 1 & 0 & 1 & 0 & 1 & 2 & 1 & 1 & & & \end{array}$

$\begin{array}{llllllllllll}2 & 2 & 1 & 1 & 3 & 1 & 1 & 1 & 1 & 1 & 0 & 1\end{array}$ species per checklist was 59 for group members and 45 for

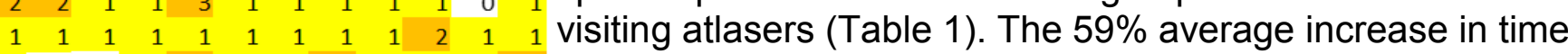

$\begin{array}{llllllllllll}1 & 0 & 0 & 1 & 2 & 1 & 1 & 2 & 1 & 1 & 1 & 2 \\ \text { spent atlasing in the pentad translated into a } 31 \% \text { increase }\end{array}$

$\begin{array}{llllllllllll}1 & 1 & 1 & 1 & 1 & 1 & 1 & 2 & 1 & 1 & 1 & 1 \\ & 0 & 1 & 1 & 2 & 1 & 1 & 2 & 1 & 1 & 2 & 1\end{array}$

$\begin{array}{llllllllllll}0 & 0 & 1 & 1 & 2 & 1 & 1 & 2 & 1 & 1 & 2 & 1 \\ 1 & 1 & 1 & 1 & 2 & 2 & 1 & 1 & 1 & 1 & 0 & 1\end{array}$

$\begin{array}{llllllllllll}1 & 0 & 1 & 2 & 2 & 1 & 1 & 0 & 1 & 2 & 1\end{array}$

$\begin{array}{lllllllllll}1 & 1 & 1 & 1 & 1 & 1 & 1 & 1 & 1 & 1 & 1\end{array}$

$\begin{array}{lllllllllll}2 & 2 & 2 & 2 & 2 & 1 & 1 & 1 & 2 & 2 & 1\end{array}$

$\begin{array}{llllllllllll}2 & 2 & 1 & 2 & 1 & 1 & 1 & 1 & 2 & 1 & 1 & 3\end{array}$

$\begin{array}{llllllllllll}2 & 2 & 2 & 2 & 1 & 2 & 1 & 1 & 0 & 2 & 3 & 1 \\ 2 & 2 & 1 & 2 & 1 & 1 & 1 & 0 & 1 & 1 & 1 & 1 \\ \text { Keeping detailed records of landowners started in January }\end{array}$

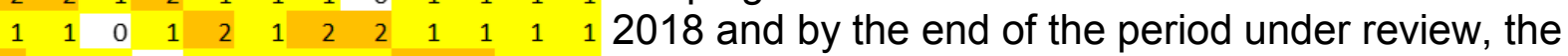

$\begin{array}{llllllllllll}2 & 1 & 1 & 0 & 1 & 1 & 1 & 1 & 2 & 2 & 1 & 1 \\ \text { database contained the details of } 126 \text { landowners for the } 75\end{array}$ 
pentads. Newsletters are distributed once a year and the first two were sent out during the review period.

\section{Discussion}

\section{Monitoring comparisons}

The U3A Stilbaai Bird Group has undertaken coordinated atlasing over two periods: December 2014 to November 2017 (van Rooyen 2018) and December 2017 to November 2019. Although atlasing for the earlier period was primarily focussed on increasing the foundational coverage, the monitoring objective also received attention from the outset. During 2015 and 2016 each pentad received at least one full protocol checklist and in 2017 (up to end November) each pentad received at least two ful protocol checklists (van Rooyen, 2018) The relative evenness of the coverage in each of these two periods will greatly facilitate the statistical analyses comparing, for example, changes in species composition between these two periods across this region (compare Figure 6 with Figure 9).

Variability in effort between atlasers or groups of atlasers will, however, prove a hindrance to making these comparisons. It will need to be taken into account in statistical analyses. It is encouraging however that there was no difference in average numbers of species after one hour and two hours of fieldwork between resident atlasers (members of the U3A Stilbaai Bird Group) and visiting atlasers.

Difference in numbers of species can be attributed to total time spent doing fieldwork. This difference is not

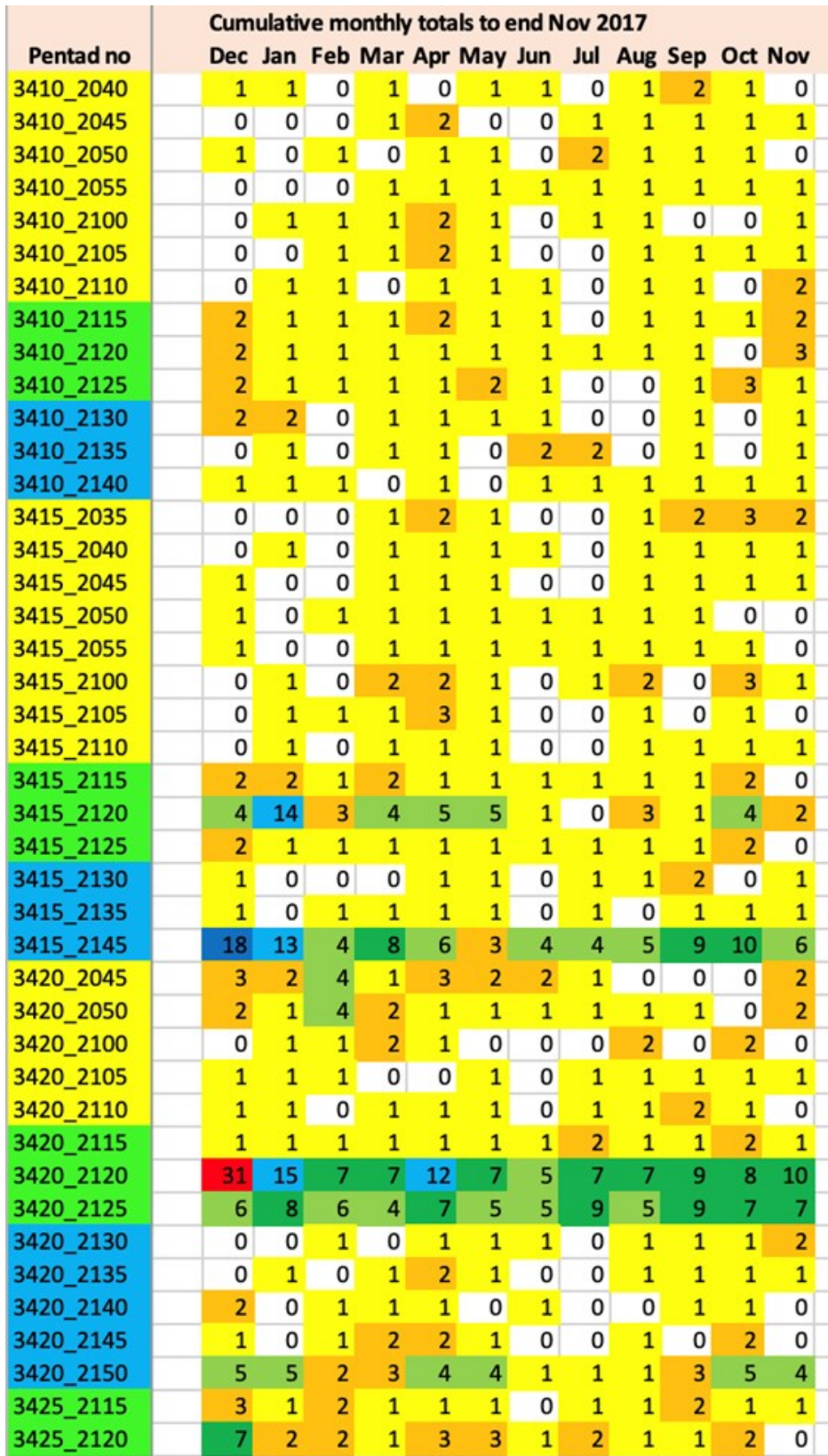

Cumulative monthly totals to end Nov 2019

Dec Jan Feb Mar Apr May Jun Jul Aug Sep Oct Nov $\begin{array}{llllllllllll}1 & 1 & 1 & 1 & 1 & 1 & 1 & 1 & 1 & 2 & 1 & 1\end{array}$ $\begin{array}{llllllllllll}1 & 0 & 0 & 1 & 2 & 1 & 1 & 2 & 1 & 1 & 1 & 2\end{array}$ $\begin{array}{llllllllllll}1 & 1 & 1 & 1 & 1 & 1 & 1 & 2 & 1 & 1 & 1 & 1\end{array}$

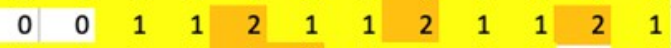
$\begin{array}{llllllllllll}1 & 1 & 1 & 1 & 2 & 2 & 1 & 1 & 1 & 1 & 0 & 1\end{array}$ $\begin{array}{llllllllllll}1 & 0 & 1 & 2 & 2 & 1 & 1 & 0 & 1 & 2 & 1 & 1\end{array}$ $\begin{array}{llllllllllll}1 & 1 & 1 & 1 & 1 & 1 & 1 & 1 & 1 & 1 & 2\end{array}$ $\begin{array}{llllllllllll}2 & 2 & 2 & 2 & 2 & 1 & 1 & 1 & 2 & 2 & 1 & 2\end{array}$ $\begin{array}{llllllllllll}2 & 2 & 1 & 2 & 1 & 1 & 1 & 1 & 2 & 1 & 1 & 3\end{array}$ $\begin{array}{llllllllllll}2 & 2 & 2 & 2 & 1 & 2 & 1 & 1 & 0 & 2 & 3 & 1\end{array}$ $\begin{array}{llllllllllll}2 & 2 & 1 & 2 & 1 & 1 & 1 & 0 & 1 & 1 & 1 & 1\end{array}$ $\begin{array}{llllllllllll}1 & 1 & 0 & 1 & 2 & 1 & 2 & 2 & 1 & 1 & 1 & 1\end{array}$ $\begin{array}{llllllllllll}2 & 1 & 1 & 0 & 1 & 1 & 1 & 1 & 2 & 2 & 1 & 1\end{array}$ $\begin{array}{llllllllllll}0 & 0 & 1 & 2 & 2 & 2 & 0 & 1 & 1 & 2 & 3 & 3\end{array}$ $\begin{array}{lllllllllll}1 & 0 & 1 & 2 & 1 & 1 & 1 & 1 & 1 & 1 & 2\end{array}$ $\begin{array}{llllllllllll}1 & 1 & 0 & 1 & 2 & 1 & 1 & 1 & 1 & 2 & 1 & 1\end{array}$ $\begin{array}{llllllllllll}1 & 1 & 1 & 2 & 2 & 1 & 1 & 2 & 1 & 1 & 1 & 0\end{array}$ $\begin{array}{lllllllllllll}1 & 0 & 1 & 1 & 1 & 2 & 2 & 1 & 1 & 1 & 2 & 0\end{array}$ $\begin{array}{llllllllllll}1 & 1 & 0 & 2 & 2 & 2 & 1 & 2 & 3 & 1 & 3 & 1\end{array}$ $\begin{array}{lllllllllllll}1 & 1 & 1 & 3 & 2 & 0 & 1 & 1 & 1 & 1 & 0\end{array}$ $\begin{array}{llllllllllll}1 & 1 & 0 & 1 & 2 & 1 & 1 & 1 & 1 & 2 & 1 & 1\end{array}$ $\begin{array}{llllllllllll}2 & 2 & 2 & 3 & 2 & 1 & 2 & 1 & 1 & 1 & 2 & 1\end{array}$ $\begin{array}{lllllllllll}18 & 5 & 7 & 6 & 7 & 3 & 1 & 4 & 4 & 5 & 2\end{array}$ $\begin{array}{llllllllllll}2 & 4 & 1 & 2 & 1 & 2 & 2 & 1 & 1 & 2 & 3 & 1\end{array}$ $\begin{array}{llllllllllll}1 & 2 & 0 & 1 & 1 & 1 & 1 & 1 & 1 & 2 & 1 & 3\end{array}$ $\begin{array}{llllllllllll}1 & 1 & 1 & 1 & 2 & 1 & 1 & 1 & 0 & 2 & 1 & 1\end{array}$ $\begin{array}{llllllllll}6 & 8 & 6 & 6 & 7 & 5 & 5 & 10 & 10 & 7\end{array}$ $\begin{array}{llllllllllll}3 & 3 & 4 & 4 & 4 & 4 & 2 & 1 & 1 & 0 & 2 & 2 \\ 2 & 2 & 4 & 4 & 1 & 1 & 1 & 2 & 2 & 1 & 1 & 2\end{array}$ $\begin{array}{lllllllllllll}1 & 1 & 1 & 3 & 1 & 1 & 0 & 3 & 3 & 1 & 2 & 0\end{array}$ $\begin{array}{llllllllllll}1 & 2 & 1 & 0 & 1 & 1 & 1 & 1 & 1 & 1 & 2 & 1\end{array}$ $\begin{array}{llllllllllll}2 & 1 & 1 & 2 & 1 & 2 & 1 & 1 & 1 & 2 & 1 & 1\end{array}$ $\begin{array}{lllllllllllll}3 & 1 & 2 & 1 & 2 & 1 & 2 & 2 & 2 & 2 & 2 & 1\end{array}$ $\begin{array}{rrrrrrrrrrrrr}43 & 18 & 12 & 11 & 14 & 11 & 7 & 12 & 10 & 15 & 12 & 14 \\ 13 & 11 & 8 & 9 & 9 & 7 & 7 & 13 & 9 & 12 & 9 & 10\end{array}$ $\begin{array}{llllllllllll}1 & 1 & 1 & 1 & 1 & 1 & 1 & 1 & 1 & 2 & 1 & 2\end{array}$ $\begin{array}{llllllllllll}1 & 1 & 1 & 1 & 2 & 2 & 1 & 0 & 1 & 1 & 1 & 2\end{array}$ $\begin{array}{llllllllllll}2 & 1 & 2 & 2 & 1 & 0 & 2 & 2 & 2 & 1 & 1 & 1\end{array}$ $\begin{array}{llllllllllll}1 & 1 & 1 & 3 & 2 & 2 & 2 & 2 & 1 & 1 & 3 & 0\end{array}$ $\begin{array}{llllllllllll}7 & 7 & 4 & 4 & 7 & 7 & 1 & 3 & 2 & 4 & 9 & 5\end{array}$ $\begin{array}{llllllllllll}5 & 3 & 2 & 1 & 1 & 2 & 1 & 2 & 2 & 2 & 2 & 1 \\ 8 & 3 & 3 & 1 & 5 & 4 & 2 & 2 & 1 & 1 & 2 & 2\end{array}$

Figure 8. Monthly distribution of the total numbers of full protocol checklists for 30 of the 75 pentads in the Hessequa Atlas Area at the start of the two-year review period in December 2017 (left) and at the end in November 2019 (right). 
proportional; a $59 \%$ increase in fieldwork time (from 3.4 to 5.4 hours) resulted in a $31 \%$ increase in the number of species (from 45 to 59 ) (Table 1).

\section{Sustainable citizen science}

The striking result of this paper is what can be achieved by a small group of citizen scientists with a modest amount of coordination. The keys to success appear to be choice and sustainability. The members of the U3A Stilbaai Bird Group are neither coerced to do particular pentads nor are they committed to a fixed amount of fieldwork every month. Instead, all members are given the opportunity to freely select pentads from the monthly list. There is no allocation of pentads to individuals in the group.

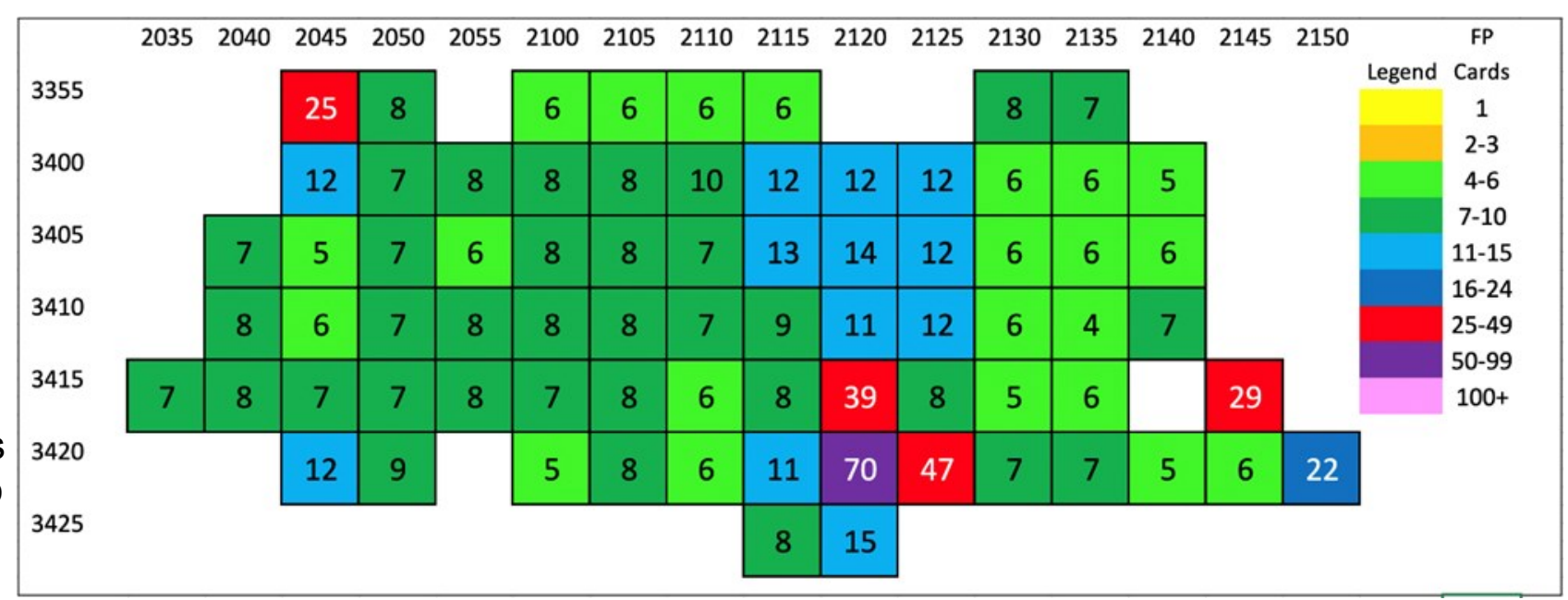

Figure 9. Numbers of full protocol checklists per pentad for the three-year period from 1 December 2014 to 30 November 2017 in the Hessequa Atlas Area (van Rooyen 2018).

Sustainability is achieved by setting a target that is both manageable and challenging. The target is 170 checklists per year, an average of 13.5 pentads per month, split among 16 teams of atlasers. Some atlasers regularly do three or four pentads per month and others pick a pentad only once in two or three months. This spread of intensity of involvement is what generates sustainability. However, if some atlasers are not able to do fieldwork in a month, because of absence on vacation, illness, etc., then the total burden is not so large that it cannot be taken up by other members of the group.

The challenge also provides motivation. There is a sense of achievement in the Bird Group that the targets are being met month-by -month and year-by-year. The human engagement described in this paper is a leading example of the kind of "persuasive design" described by Ainsley \& Underhill (2017).

\section{Contact with landowners}

In the first years of coordinated atlasing of the U3A Stilbaai Bird Group, the focus was on atlasing, and contact with landowners was limited to requesting access to farms and other privately-owned land as and when this was required to reach specific habitats. Contact was made

Table 1. Comparison of full protocol checklists submitted for the Hessequa Atlas Area by members of the Stilbaai Bird Group and by visiting atlasers. The analysis is limited to checklists submitted during the two-year period December 2017-November 2019. Averages are given.

\begin{tabular}{|l|c|c|c|c|c|}
\hline $\begin{array}{l}\text { Source of check- } \\
\text { lists }\end{array}$ & $\begin{array}{c}\text { Number } \\
\text { of } \\
\text { check- } \\
\text { lists }\end{array}$ & $\begin{array}{c}\text { Hours } \\
\text { per } \\
\text { check- } \\
\text { lists }\end{array}$ & $\begin{array}{c}\text { Species } \\
\text { after one } \\
\text { hour }\end{array}$ & $\begin{array}{c}\text { Species } \\
\text { after two } \\
\text { hours }\end{array}$ & $\begin{array}{c}\text { Total } \\
\text { species }\end{array}$ \\
\hline $\begin{array}{l}\text { U3A Stilbaai Bird } \\
\text { Group }\end{array}$ & 392 & 5.4 & 24 & 37 & 59 \\
\hline Visitors & 130 & 3.4 & 24 & 35 & 45 \\
\hline
\end{tabular}


only when required. No record was kept of contacts made. However, due to issues involving security and land redistribution, the characteristic behaviour of atlasers, even on a public road, makes landowners anxious and suspicious: a slow-moving vehicle stopping regularly, people getting out and scanning the fields with binoculars. The landowners in Hessequa Atlas Area are in general remarkably friendly, but an undesirable pattern develops when landowners have to get into a vehicle and drive to investigate what is understandably regarded as potentially criminal activity, especially over weekends.

To resolve this incipient problem, a database was created with names and contact details of all the landowners with whom contact is made while atlasing. These people constitute the "Friends of the U3A Stilbaai Bird Group". The landowners fall into three broad categories. The first consists of those from whom access is required to reach specific habitats on their properties; the second are Plate 5. View from about $10 \mathrm{~km}$ east of Riversdale looking northwest towards the Langeberg. The those from whom access is not required, but Goukou River is in the middle distance. The V in the mountain at centre is where Garcia pass is going who express an interest in the activity; and through the mountain with Sleeping Beauty just to the left of it. the third group consists of those who simply want to be aware in advance that atlasers are going to be present in their areas.

is located, a bird list for the pentad, and a copy of the Bird Group's newsletter.

As landowners are added to the database they receive an email that introduces them to the U3A Stilbaai Bird Group and to the bird atlas project. They also receive a map of the pentad in which their property

Maps of each pentad showing private roads, the locations of landowners within it, as well as their contact details, are made available to members of the U3A Stilbaai Bird Group. The information 


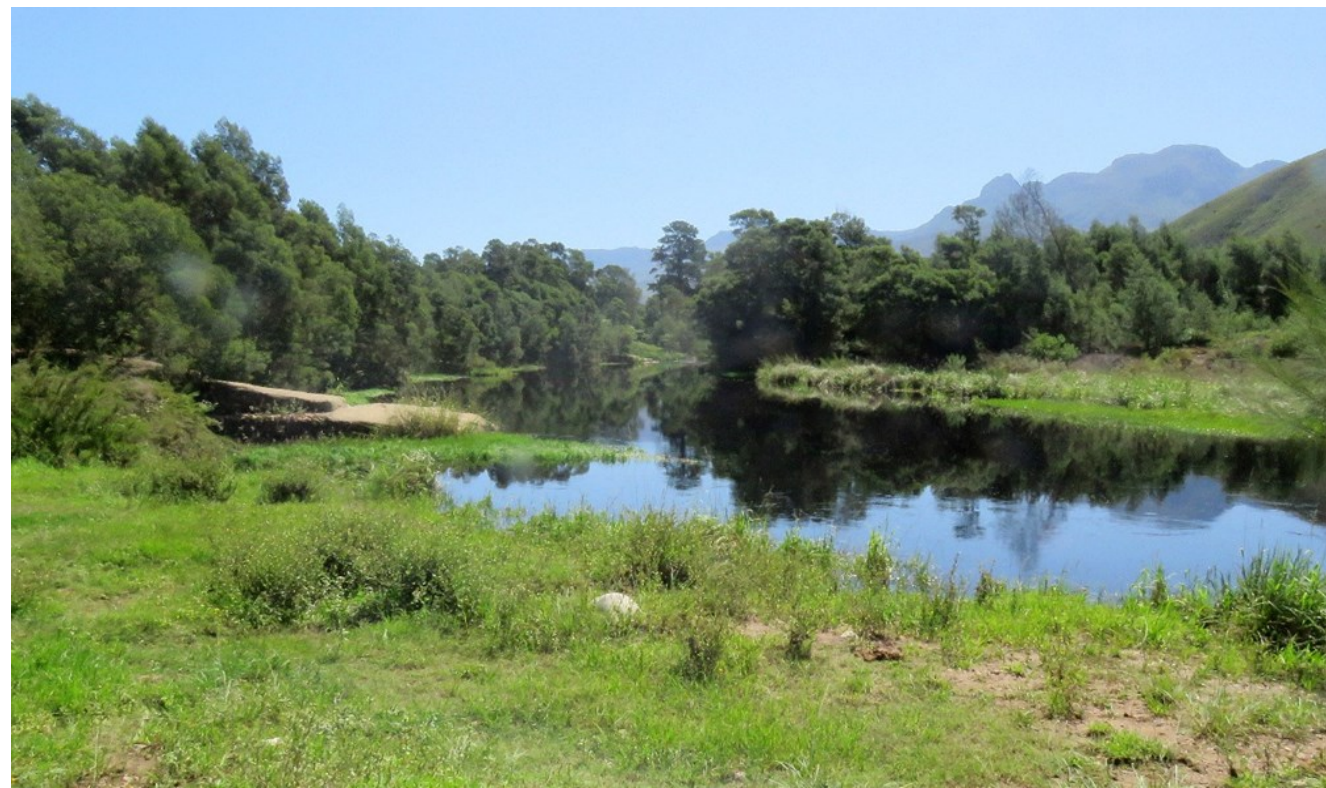

Plate 6. The Duiwenhoksrivier has its source in the Langeberg mountain range. This view is near Grootvadersbosch.

is stored on Dropbox and is updated as new landowners become part of the "Friends" group. As described above, each atlaser informs relevant landowners prior to making an atlas trip, carries project identification material, and displays magnetic plates on their vehicles. This approach has been received positively by the landowners. The intention is to actively expand the "Friends" list as more contacts are made.

The "Friends" group constitutes an opportunity to interest landowners in the birds and general biodiversity on their properties. They receive an annual newsletter as well as an updated bird list.

\section{Conclusion}

The monitoring strategy, using the bird atlas protocol, proposed by van Rooyen (2018) has proved feasible, and the first two-year cycle has been successfully completed. U3A Stilbaai Bird Group has continued to contribute to SABAP2 during the two years from December 2017 to November 2019. A protocol for systematic atlasing has been designed in a way which sets a new standard for the monitoring phase of the project. The protocol is sustainable. The Bird Group intends to continue the monitoring fieldwork indefinitely.

The Bird Group has also designed systems which improve relationships with landowners. These are essential for sustained access to privately-owned land. It has established a broad support base in the farming community. There is potential to build biodiversity awareness through this relationship.

\section{Acknowledgements}

Since October 2014, the atlasers of the U3A Stilbaai Bird Group have participated in SABAP2 in the structured patterns described here and van Rooyen (2018). They have given the project their full support and we celebrate their willingness to be coordinated in this way. They are Renier Balt, Dirk Bosman, Patrick and Alice Duddy, Pieter and Louisa du Toit, Ben and Joekie Jovner, Karel and Amanda Nel, Derick Oosthuizen, Phil and Esther Scheffer, Hennie and Gerda Smit, Marguerite Smit, Menno and Krysia Stenvert, Terry and Maria Terblanche, Annelie van Lill, Johan and Estelle van Rooyen, Rita van Rooyen and John and Jeannie Willemse.

The friendly support of the landowners in the Hessequa Atlas Area is deeply appreciated. Access is invariably given when requested and the project benefits enormously from their suggestions of places to visit on their properties. 
Visitors to the area generate large numbers of full-protocol checklists. www.researchgate.net/

Their contribution to the project is extremely valuable. The SABAP2 publication/314189706 The Second Southern African Bird Atlas Pr team and specifically Sanjo Rose and Ernst Retief provided support oject protocol process product

and sorted out administrative problems. Andrew de Blocq who does

the vetting for the Western Cape helped with prompt decisions on the many Out-of-Range forms generated by the Bird Group.

van Rooyen JA 2018. Systematic atlasing in Hessequa - moving from mapping to monitoring. Biodiversity Observations 9.10:1-13. Available online at https://journals.uct.ac.za/index.php/BO/article/view/508

Last but not least Estelle van Rooyen, Johan's wife, atlas partner, bird photographer, proof reader and supporter.

\section{References}

Ainsley J, Underhill LG 2017. Gamification (persuasive design) in the Southern African Bird Atlas Project. Vogelwelt 137: 19-22. Available https://www.researchgate.net/

publication/314189964 Gamification persuasive design in the Seco nd Southern African Bird Atlas Project

U3A Stilbaai 2015. U3A Stilbaai Voëlgroep/U3A Stilbaai Bird Group. Available online at http://www.u3astilbaai.org/birdgroup/index.html.

Underhill LG 2016. The fundamentals of the SABAP2 protocol. Biodiversity Observations 7.42:1-12. Available online at https:// journals.uct.ac.za/index.php/BO/article/view/335

Underhill LG, Brooks M 2016. SABAP2 after nine years, mid 2007mid 2016: coverage progress and priorities for the Second Southern African Bird Atlas Project. Biodiversity Observations 7.37:1-17. Available online at https://journals.uct.ac.za/index.php/BO/article/ $\underline{\text { view/330 }}$

Underhill LG, Brooks M, Loftie-Eaton M 2017. The Second Southern African Bird Atlas Project: protocol, process, product. Vogelwelt 137: 64-70. Available online at https://

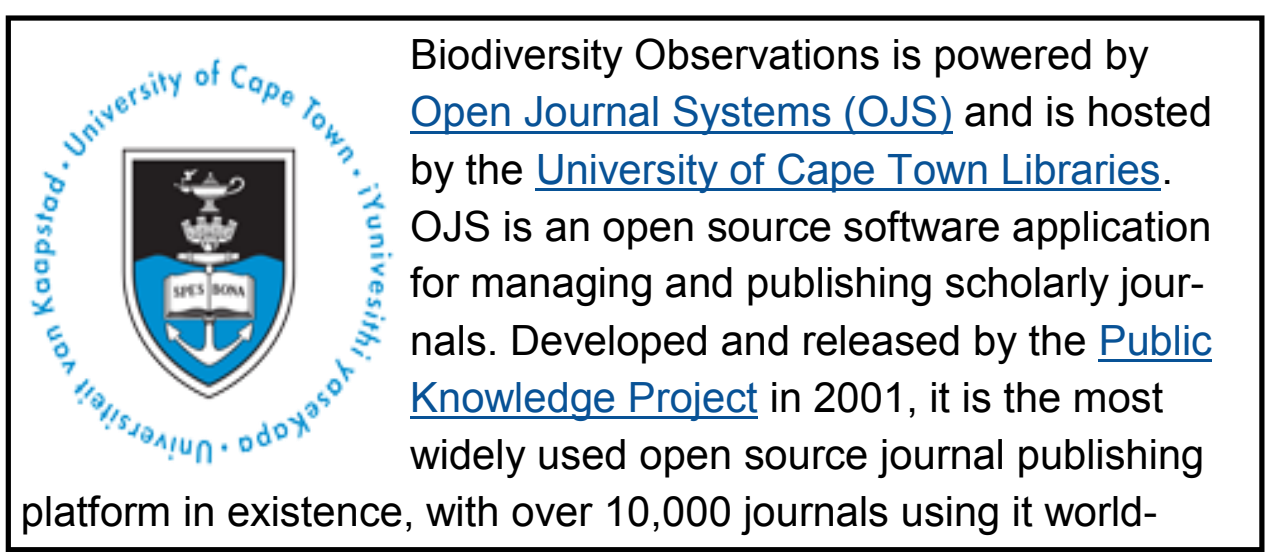




\section{Biodiversity Observations}

The scope of Biodiversity Observations includes papers describing observations about biodiversity in general, including animals, plants, algae and fungi. This includes observations of behaviour, breeding and flowering patterns, distributions and range extensions, foraging, food, movement, measurements, habitat and colouration/plumage variations. Biotic interactions such as pollination, fruit dispersal, herbivory and predation fall within the scope, as well as the use of indigenous and exotic species by humans. Observations of naturalised plants and animals will also be considered. Biodiversity Observations will also publish a variety of other interesting or relevant biodiversity material: reports of projects and conferences, annotated checklists for a site or region, specialist bibliographies, book reviews and any other appropriate material. Further details and guidelines to authors are on the journal website (https://journals.uct.ac.za/index.php/BO/).

ISSN 2219-0341

Editors: PN Laver and LG Underhill

biodiversity

observations

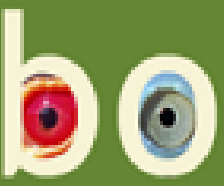

